\title{
Calibration Factor for LR 115 Type II Detectors Used to Measure Indoor ${ }^{220} \mathrm{Rn}$
}

Nguyen Thi Thu Ha*, Trinh Van Giap, Nguyen Van Khanh, Le Dinh Cuong, Pham Bao Ngoc and Nguyen Thi Oanh

Institute for Nuclear Science and Technology (INST), Hanoi City, Vietnam

\begin{abstract}
Major aim of the paper is to determine calibration factor for LR 115 type II detectors used to measure indoor ${ }^{220} \mathrm{Rn}$. To determine calibration factor, LR 115 detectors were fixed on top and bottom inside urban cup chamber and sent to NIRS, Japan to ${ }^{220} \mathrm{Rn}$ calibration exposure. After detectors have been calibration exposure at NIRS, authors carried out following all steps of procedure, which set up at laboratory in INST, Vietnam. This paper discusses the experimental method that is used in calculating the calibration factor of ${ }^{220} \mathrm{Rn}$ inside the urban cup, calibration factors (CF) were determined by experimental with detectors placed at top and bottom inside urban cup were $0.023 \pm 0.004$ and 0.038 \pm 0.007 (tracks. $\mathrm{cm}^{-2} / \mathrm{Bq} \cdot \mathrm{m}^{-3} \cdot \mathrm{d}$ ), respectively. The curve between integrated ${ }^{220} \mathrm{Rn}$ concentration and tracks density with factor $\mathrm{R}^{2}=0.96$ and 0.97 at top and bottom inside urban cup, respectively. In order to precision evaluation, authors used 20 couple of LR-115 detectors at $8 \mathrm{~cm}$ detector-source distance with relative standard deviation less than $1.48 \%$.
\end{abstract}

Keywords: LR-115 type- II; Rn-220; Spark counter

\section{Introduction}

Thoron $\left({ }^{220} \mathrm{Rn}\right)$ is a natural radon $\left({ }^{222} \mathrm{Rn}\right)$ isotope with a relatively short half-life (55.6 s), comparing with ${ }^{222} \mathrm{Rn}$ (3.82 day). Therefore, its indoor concentrations depend strongly on the distance from the point where ${ }^{220} \mathrm{Rn}$ is emanated [1-3]. Therefore, short half-life ${ }^{220} \mathrm{Rn}$ which makes accurate measurements of ${ }^{220} \mathrm{Rn}$ concentrations extremely difficult to obtain. Nevertheless, the accurate measurement of ${ }^{220} \mathrm{Rn}$ in the environment is an important task from the viewpoint of radiation protection [4]. Determining the radiation hazard from ${ }^{220} \mathrm{Rn}$ and its progeny has become imperative. Additionally, determining an accurate activity concentration for ${ }^{220} \mathrm{Rn}$ and its progeny needs to concern calibration factor (CF).

Besides this large concern in ${ }^{222} \mathrm{R}$, importance of ${ }^{220} \mathrm{Rn}$ has recently been recognized, ${ }^{220} \mathrm{Rn}$ is present everywhere together with ${ }^{222} \mathrm{R}$, and a quantity of ${ }^{220} \mathrm{Rn}$ is sometimes much larger than that of ${ }^{222} \mathrm{R}$ at a certain position in dwellings Why was ${ }^{220} \mathrm{Rn}$ underestimated in the past studies? The following reasons can be considered: there are many difficulties in measurement and calibration ${ }^{220} \mathrm{Rn}$, there are no epidemiological data related to ${ }^{220} \mathrm{Rn}$ exposure and the ${ }^{220} \mathrm{Rn}$ risk seems to be negligible.

What is a clear difference between mine studies and indoor studies on ${ }^{222} \mathrm{Rn}$ ? It is the presence of ${ }^{220} \mathrm{Rn}$. When considering a radon risk in indoor studies, special attention should be paid to ${ }^{220} \mathrm{Rn}$ present together with ${ }^{222} \mathrm{Rn}$. However, recent statements about the contribution of ${ }^{220} \mathrm{Rn}$ on the dose have to be reconsidered. Studies have shown that people living in environments with high ${ }^{220} \mathrm{Rn}$ concentration in Brazil, China and India are receiving a high dose from ${ }^{220} \mathrm{Rn}[2,5-9]$. This is the reason why ${ }^{232} \mathrm{Th}$ rich environment has to be taken into account in radiological point of view to prevent elevated risk originated from high ${ }^{220} \mathrm{Rn}$ levels.

The aim of this study was to determine calibration factor CF to measure ${ }^{220} \mathrm{Rn}$ used to LR-115 type II detector is placed inside Urban cup. Detectors are fixed on the top and bottom inside urban cup and sent to NIRS, Japan to ${ }^{220} \mathrm{Rn}$ calibration exposure, after calibration exposure detectors sent back to Vietnam. Detectors were etched with $2.5 \mathrm{~N} \mathrm{NaOH}$ solution following the etching protocols in INST's lab, Vietnam. Tracks developed were counted using a spark counter. The CF $\left(\right.$ tr. $\mathrm{cm}^{-2}$ per Bq.d. $\mathrm{m}^{-3}$ ) for individual experiment was obtained by relating these tracks with the respective measured gas concentrations (Tables 1 and 2).

\section{Materials and Methods}

\section{Equipment}

LR-115 type II detector: Using $12 \mu \mathrm{m}$ thick LR-115 type II cellulose nitrate alpha track detectors manufactured by Kodak Pathe, France. The detectors consist of an active layer of red cellulose nitrate on a $100 \mu \mathrm{m}$ clear polyester base substrate as shown in Figure 1. Detectors used with dimensions $3 \times 3 \mathrm{~cm}$.

Urban cup chamber: It is commonly named as the "Karlsruhe" with inner base radius of $2.35 \mathrm{~cm}$, top radius of $3.35 \mathrm{~cm}$ and height of $4.8 \mathrm{~cm}$. There are holes in the brim of the chamber, which allow air to flow in and out of the chamber. LR-115 detectors are fixed in top and bottom inside urban cup as shown in Figure 2.

Spark counter system: Spark Counter Model 9201 T-G has been researched and manufactured since 1994 at INST, Vietnam.

Etching system: The system as shown in Figure 3. The etching solution $\mathrm{NaOH} 2.5 \mathrm{M}$ was maintained at $60 \pm 1^{\circ} \mathrm{C}$ in a water bath. The water bath was sheltered by a plastic cover to reduce water loss. The region of damage around each track was extended by the etchant so that the tracks became visible as small holes on the surface of the detector. After $1.5 \mathrm{~h}$, chemical etching the films are rinsed in running cold water for 30 minutes, dried, and put back into a plastic bag for protection.

${ }^{220} \mathrm{Rn}$ calibration system at NIRS, Japan: The NIRS developed a compact ${ }^{220} \mathrm{Rn}$ calibration chamber. The chamber consists of four components: exposure system, calibration system, monitoring system and humidity control system. A 150L stainless steel vessel is used as

*Corresponding author: Nguyen Thi Thu $\mathrm{Ha}$, Institute for Nuclear Science and Technology (INST), Vietnam 179 Hoang Quoc Viet Street, Cau Giay District, Hanoi City, Vietnam, Tel: 8443 8363295; E-mail: thuhaus@gmail.com

Received April 26, 2017; Accepted May 23, 2017; Published June 16, 2017

Citation: Ha NTT, Giap TV, Khanh NV, Cuong LD, Ngoc PB, et al. (2017) Calibration Factor for LR 115 Type II Detectors Used to Measure Indoor ${ }^{220} \mathrm{Rn}$. J Environ Anal Toxicol 7: 476. doi: 10.4172/2161-0525.1000476

Copyright: (c) $2017 \mathrm{Ha} \mathrm{NTT}$, et al. This is an open-access article distributed under the terms of the Creative Commons Attribution License, which permits unrestricted use, distribution, and reproduction in any medium, provided the original author and source are credited. 
Citation: Ha NTT, Giap TV, Khanh NV, Cuong LD, Ngoc PB, et al. (2017) Calibration Factor for LR 115 Type II Detectors Used to Measure Indoor ${ }^{220}$ Rn. J Environ Anal Toxicol 7: 476. doi: 10.4172/2161-0525.1000476

\begin{tabular}{|c|c|c|c|c|}
\hline $\begin{array}{c}\text { Expt. } \\
\text { No. }\end{array}$ & $\begin{array}{c}\text { Exposure } \\
\text { duration } \\
\text { (h) }\end{array}$ & ${ }^{220} \mathbf{R n}\left(\mathbf{k B q} / \mathbf{m}^{3}\right)$ & $\begin{array}{c}\text { Tracks } \\
\left.\text { (tr.cm }^{-2}\right)\end{array}$ & $\begin{array}{c}\text { CF } \\
\left.\text { (tr.cm }^{-2} \text { per Bq. } \mathbf{m}^{-3} . \mathbf{d}\right)\end{array}$ \\
\hline 1 & 22 & 24 & 472.8 & 0.021 \\
\hline 2 & 22 & 24 & 383.0 & 0.017 \\
\hline 3 & 40 & 25.4 & 901.0 & 0.021 \\
\hline 4 & 40 & 25.4 & 1254.0 & 0.030 \\
\hline 5 & 66 & 30.5 & 2121.0 & 0.025 \\
\hline 6 & 66 & 30.5 & 2124.0 & 0.025 \\
\hline & & Average & & $0.023 \pm 0.004$ \\
\hline
\end{tabular}

Table 1: Calibration factor (CF) for LR-115 type II detector at top inside urban cup.

\begin{tabular}{|c|c|c|c|c|}
\hline $\begin{array}{c}\text { Expt. } \\
\text { No. }\end{array}$ & $\begin{array}{c}\text { Exposure } \\
\text { duration } \\
\text { (h) }\end{array}$ & ${ }^{220} \mathbf{R n}\left(\mathbf{k B q} / \mathbf{m}^{3}\right)$ & $\begin{array}{c}\text { Tracks } \\
\left.\text { (tr.cm }^{-2}\right)\end{array}$ & $\begin{array}{c}\text { CF } \\
\left.\text { (tr.cm }^{-2} \text { per Bq. } \mathbf{m}^{-3} . \mathbf{d}\right)\end{array}$ \\
\hline 1 & 22 & 24 & 573.6 & 0.026 \\
\hline 2 & 22 & 24 & 782.8 & 0.036 \\
\hline 3 & 40 & 25.4 & 1799.0 & 0.042 \\
\hline 4 & 40 & 25.4 & 1758.6 & 0.042 \\
\hline 5 & 66 & 30.5 & 3635.8 & 0.043 \\
\hline 6 & 66 & 30.5 & 3363.2 & 0.040 \\
\hline & & Average & & $0.038 \pm 0.007$ \\
\hline
\end{tabular}

Table 2: Calibration factor (CF) for LR-115 type II detector at bottom inside urban cup.

the exposure chamber. In order to make a homogeneous distribution of ${ }^{220} \mathrm{Rn}$ concentration, an inner fan is installed. Lantern mantles are used as the practical ${ }^{220} \mathrm{Rn}$ source. The ${ }^{220} \mathrm{Rn}$ concentration is measured using a single scintillation cell method [6].

\section{Experiment}

The experimental arrangement is shown in Figure 4, authors prepared fifteen detectors LR-115 with dimensions $3 \times 3 \mathrm{~cm}$ and six urban cup chambers. Twelve Detectors is fixed in top and bottom inside six urban cup chambers, three retained detectors to background counter. Then chambers with detectors is wrapped by polyethylene and sent to NIRS, Japan to calibration exposure. Procedure of calibration exposure is helped by Sorimachi et al. [6-9]. After calibration, exposure detectors were sent back to Vietnam. Detectors were etched with $2.5 \mathrm{~N}$ $\mathrm{NaOH}$ solution at constant temperature $60 \pm 1^{\circ} \mathrm{C}$ following the etching protocols which set up at laboratory in INST, Vietnam. Tracks developed were counted using a spark counter is shown in Figure 5. The CF (tr. $\mathrm{cm}^{-2}$ per $\mathrm{Bq} \mathrm{d} \mathrm{m}^{-3}$ ) for individual experiment was obtained following equation (1). The experimental results were shown in Tables 1 and 2.

$$
\mathrm{CF}=\frac{24 *\left(\rho_{\mathrm{T}}-\rho_{\mathrm{B}}\right)}{\mathrm{C}_{\mathrm{T}_{\mathrm{n}}}{ }^{*} \mathrm{H}}
$$

where:

$\mathrm{C}_{\mathrm{Tn}}:{ }^{220} \mathrm{Rn}$ calibration exposure concentration $\left(\mathrm{Bq} / \mathrm{m}^{3}\right)$

$\rho_{\mathrm{T}}$ : Density of calibration exposure detectors $\left(\mathrm{tr} . \mathrm{cm}^{-2}\right)$

$\rho_{\mathrm{B}}$ : Density of background detectors $\left(\operatorname{tr} . \mathrm{cm}^{-2}\right)$

$\mathrm{H}$ : Exposure duration (h)

CF: Calibration factor (tr.cm² per Bq. $\left.\mathrm{m}^{-3} \cdot \mathrm{d}\right)$

\section{Results and Discussion}

Table 1 summarizes the results of the average CF obtained from a

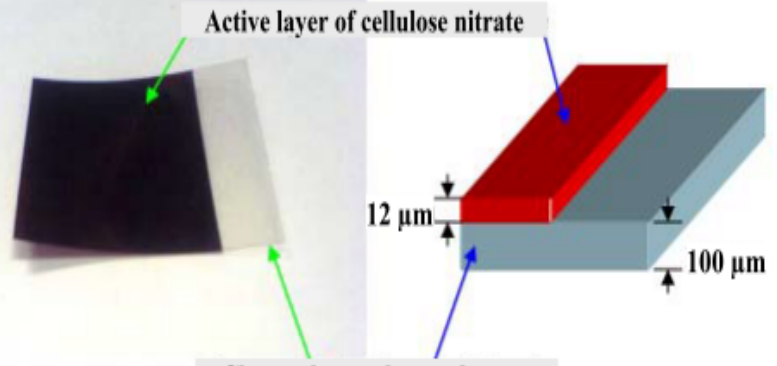

Clear polyester base substrate

Figure 1: LR-115 type II detector $(3 \times 3 \mathrm{~cm})$.

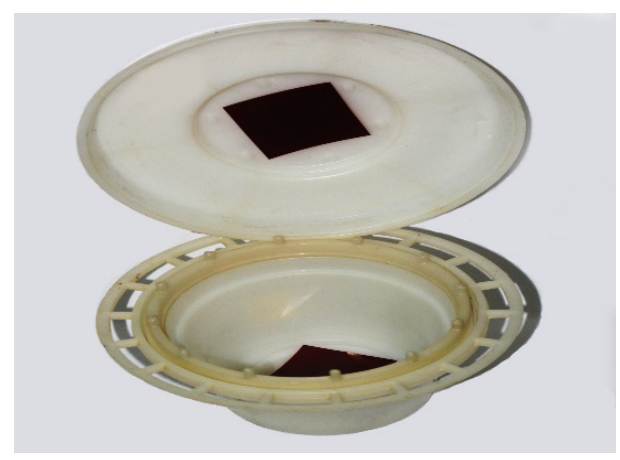

Figure 2: Urban cup chamber.

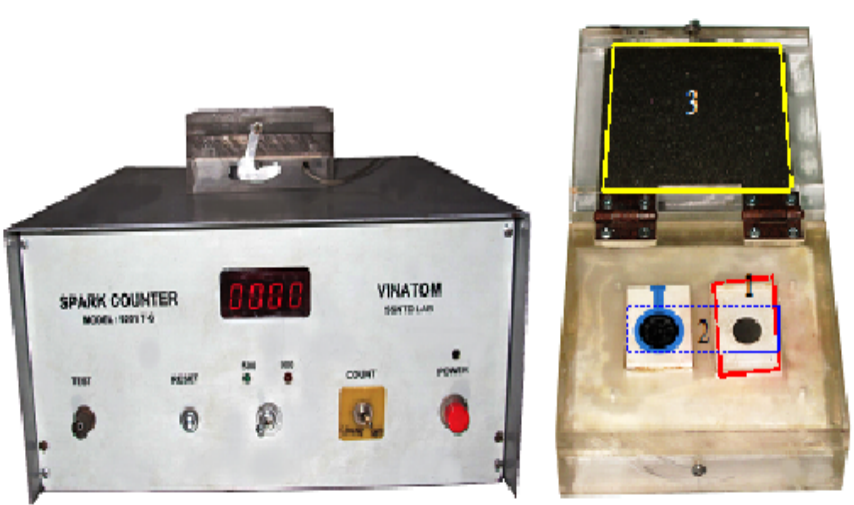

Figure 3: Spark Counter system.

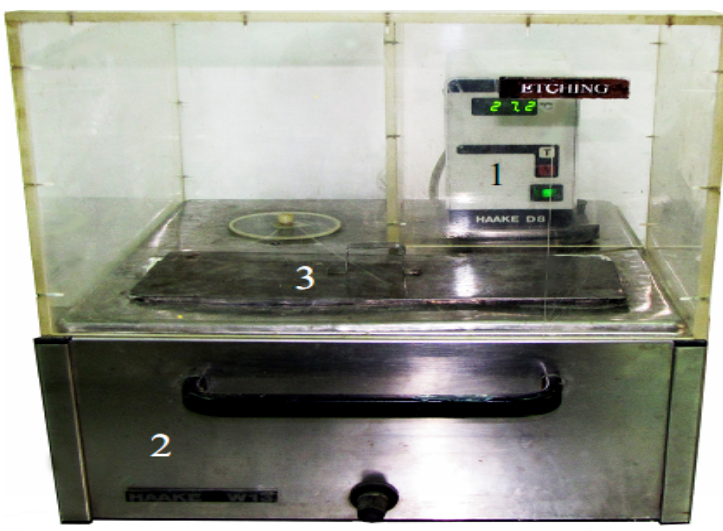

Figure 4: Etching system. 
Citation: Ha NTT, Giap TV, Khanh NV, Cuong LD, Ngoc PB, et al. (2017) Calibration Factor for LR 115 Type II Detectors Used to Measure Indoor ${ }^{220}$ Rn. J Environ Anal Toxicol 7: 476. doi: 10.4172/2161-0525.1000476
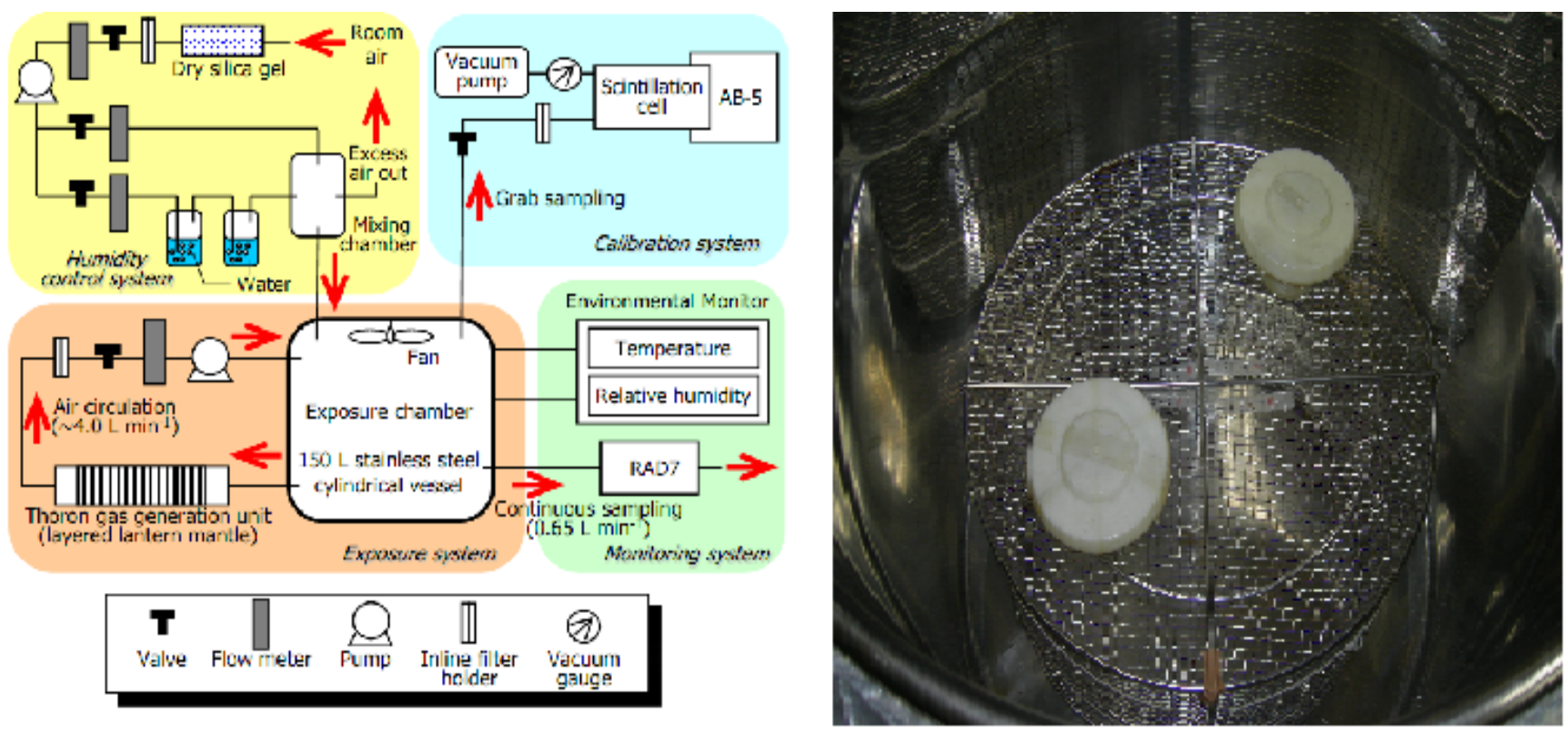

Figure 5: NIRS ${ }^{220} \mathrm{Rn}$ chamber system. Source: Sorimachi et al. [8]

few experiments with varying concentrations and exposure durations for LR-115 type II detector is placed in top inside urban cup was 0.023 \pm 0.004 (tracks. $\mathrm{cm}^{-2} / \mathrm{Bq} . \mathrm{m}^{-3}$.d). Relationship between integrated thoron concentration and track density at top inside urban cup as shown in Figure 6 with $\mathrm{R}^{2}=0.96$.

Table 2 summarizes the results of the average CF obtained from a few experiments with varying concentrations and exposure durations for LR-115 type II detector is placed in bottom inside urban cup was $0.038 \pm 0.007$ (tracks.cm ${ }^{-2} /$ Bq. ${ }^{-3} . \mathrm{d}$ ). Relationship between integrated thoron concentration and track density at bottom inside urban cup as shown in Figure 7 with $\mathrm{R}^{2}=0.97$.

\section{Conclusions}

A practical methodology has been developed to determine average calibration factors (CF) for LR-115 type II detector. Precision evaluation authors used 20 couples of LR-115 detector at $8 \mathrm{~cm}$ detector-source distance with relative standard deviation less than $1.48 \%$.

The results of the average CF obtained from a few experiments with varying concentrations and exposure durations for LR-115 type II detector is placed in top inside urban cup was $0.023 \pm 0.004$ (tracks. $\mathrm{cm}^{-2} / \mathrm{Bq} . \mathrm{m}^{-3} . \mathrm{d}$ ). Relationship between integrated ${ }^{220} \mathrm{Rn}$ concentration and track density at top inside urban cup as shown in Figure 5 with $\mathrm{R}^{2}=0.96$.

The results of the average CF obtained from a few experiments with varying concentrations and exposure durations for LR-115 type II detector is placed in bottom inside urban cup was $0.038 \pm 0.007$ (tracks. $\mathrm{cm}^{-2} / \mathrm{Bq} \cdot \mathrm{m}^{-3} \cdot \mathrm{d}$ ). Relationship between integrated ${ }^{220} \mathrm{Rn}$ concentration and track density at bottom inside urban cup as shown in Figure 6 with $\mathrm{R}^{2}=0.97$.

\section{Acknowledgments}

The authors are grateful to Dr. Trinh Van Giap, the Board of Institute for Nuclear Science and Technology(INST) for professional advice on several aspects of the ${ }^{220} \mathrm{Rn}$ measurements. Authors are also grateful to Dr. Sorimachi et al. for their help during calibration exposure of detectors.

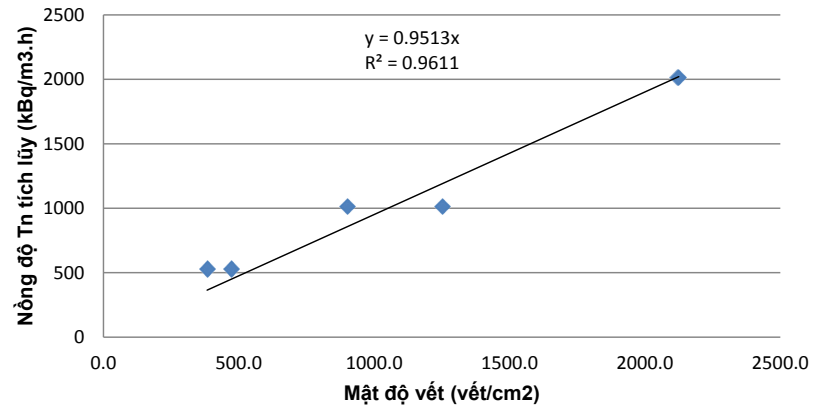

Figure 6: Relationship between integrated thoron concentration and track density at top inside urban cup.

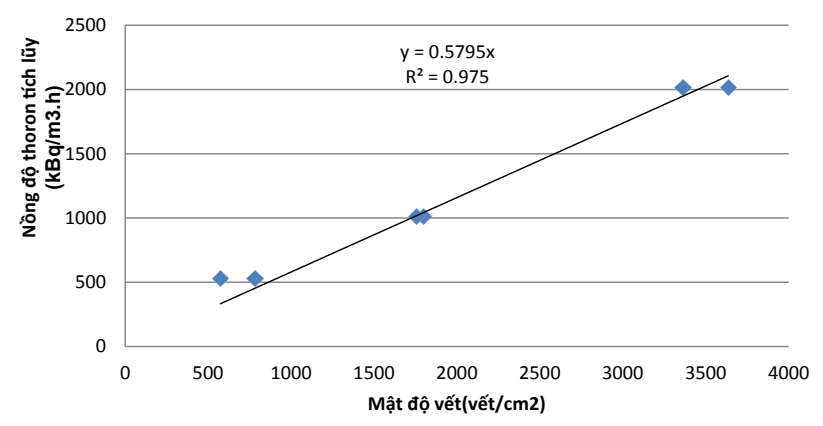

Figure 7: Relationship between integrated thoron concentration and track density at bottom inside urban cup.

\section{References}

1. Kobayashi S (1994) The passive radon-thoron discriminative dosimeter for practical use. Japan J Health Phy 29: 155-166.

2. Eappen KP, Sahoo SK, Ramachandran TV, Maya YS (2008) Calibration factor for thoron estimation in cup dosimeter, Radiat Meas 24: 410-414.

3. Nuccetelli C (1998) The thoron issue: monitoring activities, measuring techniques and dose conversion factors. Radiat Prot Dosim 78: 59-64. 
Citation: Ha NTT, Giap TV, Khanh NV, Cuong LD, Ngoc PB, et al. (2017) Calibration Factor for LR 115 Type II Detectors Used to Measure Indoor ${ }^{220}$ Rn. J Environ Anal Toxicol 7: 476. doi: 10.4172/2161-0525.1000476

Page 4 of 4

4. Tokonami (2005) International Congress Series 1276 Elsevier, The Netherlands p 151.

5. Tokonami S (2005) Summary of dosimetry (radon and thoron) studies. Int Congr 1276: 151-154.

6. Sorimachi A, Ishikawa T, Janik M, Tokonami S (2010) Quality assurance and quality control for thoron measurement at NIRS. Radiat Prot Dosim 141: 367-370.
7. Sorimachi A, Tokonami S, Takahashi H, Kobayashi Y (2008) Performance of NIRS thoron chamber system. In: The American Institute of Physics (AIP) Conference Proceedings Series 1034: 206-209.

8. Sorimachi A, Sahoo SK, Tokonami S (2009) Generation and control of thoron emanated from lantern mantles. Rev Sci Instrum 80: 015104.

9. Yamada Y, Sun Q, Tokonami S, Akiba S, Zhuo W, et al. (2006) Radon-thoron discriminative measurements in Gansu province, China, and their implication for dose estimates. J Toxicol Environ Health A 69: 723-734. 